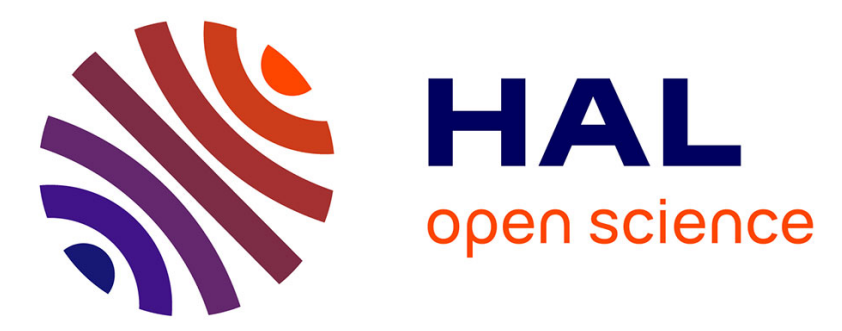

\title{
Axial claw pole motor: harmonic torque estimation using finite element method
}

Dominique Giraud, Baptiste Ristagno, Denis Netter, Julien Fontchastagner, Nicolas Labbe, Vincent Lanfranchi

\section{- To cite this version:}

Dominique Giraud, Baptiste Ristagno, Denis Netter, Julien Fontchastagner, Nicolas Labbe, et al.. Axial claw pole motor: harmonic torque estimation using finite element method. COMPEL: The International Journal for Computation and Mathematics in Electrical and Electronic Engineering, 2020, 39 (5), pp.1157-1167. 10.1108/COMPEL-01-2020-0024 . hal-02930788

\section{HAL Id: hal-02930788 \\ https://hal.science/hal-02930788}

Submitted on 29 Sep 2020

HAL is a multi-disciplinary open access archive for the deposit and dissemination of scientific research documents, whether they are published or not. The documents may come from teaching and research institutions in France or abroad, or from public or private research centers.
L'archive ouverte pluridisciplinaire HAL, est destinée au dépôt et à la diffusion de documents scientifiques de niveau recherche, publiés ou non, émanant des établissements d'enseignement et de recherche français ou étrangers, des laboratoires publics ou privés.

\section{(ㄷ)(1) $\$$}

Distributed under a Creative Commons Attribution - NonCommerciall 4.0 International 


\title{
Axial claw pole motor: harmonic torque estimation using finite element method
}

\author{
Dominique Giraud $^{1,2}$, Baptiste Ristagno ${ }^{1,2}$, Denis Netter ${ }^{1}$, \\ Julien Fontchastagner ${ }^{1}$, Nicolas Labbe ${ }^{2}$, Vincent Lanfranchi ${ }^{3}$, \\ ${ }^{1}$ Université de Lorraine, GREEN, 54500 Vandoeuvre-lès-Nancy, France \\ ${ }^{2}$ Valeo Electrical System, 38070 Saint-Quentin-Fallavier, France \\ ${ }^{3}$ Université de Technologie de Compiègne, LEC, 60203 Compiègne, France
}

\begin{abstract}
Purpose - This paper aims to propose a method to evaluate the information obtained on harmonics calculations and to estimate the precision of results using finite element method for an innovative motor topology in which some well-known meshing rules are difficult to apply.

Design/Methodology/Approach - The same magnetostatic problem is solved with several mesh sizes using both scalar and vector potentials magnetics formulations on a complex topology, an axial claw pole motor (ACPM). The proposed method lies in a comparison between the two weak formulations to determine what information is obtained on harmonics calculations and to estimate its precision. Moreover, an original mesh method is applied in the air gap to improve the numerical results.

Finding - The precision on harmonics calculations using finite element method on an ACPM is estimated. For the proposed motor and mesh, only the mean value (even with large mesh) and the first harmonic (with fine mesh) of torque are calculated with a good accuracy. This results confirm that the non-respect of the meshing rules have a strong impact on the results and that scalar and vector potentials magnetics formulations do not give exactly the same results. Before using torque harmonics values in vibration calculations, a finite element model has to be validated by using both fomulations.

Research limitations implications - This method is time-consuming and only applied on an ACPM in this work.

Originality/Value - The axial claw pole motor, for which the classic meshing rules cannot be applied, is a complex topology very under-studied. To improve the calculation of space harmonics, the authors proposed to split the airgap into four parts. Then in the two central parts, the meshing step of the structured mesh is equal to the rotating step.
\end{abstract}


Keywords - Axial flux machines, Finite element method, Mesh generation, Claw pole motor, Mesh

\section{Introduction}

Nowadays there is a huge need of precise information about vibrations and acoustics in many fields as in automotive traction. That is why harmonic calculations of physical values, as torque harmonics is widely spreaded (Wu et al. 2019). In fact, several studies, both experimental (Zhu \& Leong 2012)(Lee \& Ha 2018)(Beccue et al. 2005)(Nam et al. 2017) and using finite element method (Zhao et al. 2015) (Chaieb et al. 2008), deal with torsional vibration in electric motor because of torque harmonics. Nevertheless, the results about high-order harmonics using finite element method depend on many parameters and are strongly linked to mesh quality at the air-gap interface.

In this paper, a procedure is presented to deal with the influence of the mesh on the results for an axial claw pole motor (ACPM) (Labbe \& Savinois 2017). Indeed, some meshing rules (Davat et al. 1985) are well known for harmonics calculation but unfortunately, are difficult to apply for this topology. In these case, there is a lack of tools to analyse the confidence about simulation results on high-order harmonics. The authors propose to solve magnetostatic problem for several meshing with both scalar and vector potentials magnetics formulations. Then, output data will be treated to determine what information is obtained on harmonics calculations and to estimate its precision with a comparison between the two weak formulations. Moreover, an original mesh method is applied in the airgap to improve the numerical results. The method is tested on a model using the open-source Onelab interface, linking Gmsh (Geuzaine \& Remacle 2009). and GetDP (Dular \& Geuzaine 2019) for torque harmonics calculation.

\section{Problem}

\subsection{Meshing rules}

In Finite Element Method (FEM)-based simulations, some meshing rules are well known to calculate torque harmonics for radial rotating machines (Davat et al. 1985). Stator and rotor must have the same number of elements at airgap interface with a meshing step equals to the rotating step as it can be seen in Figure 1. To apply this rules, the least common multiple is generally used to define the number of mesh element. 


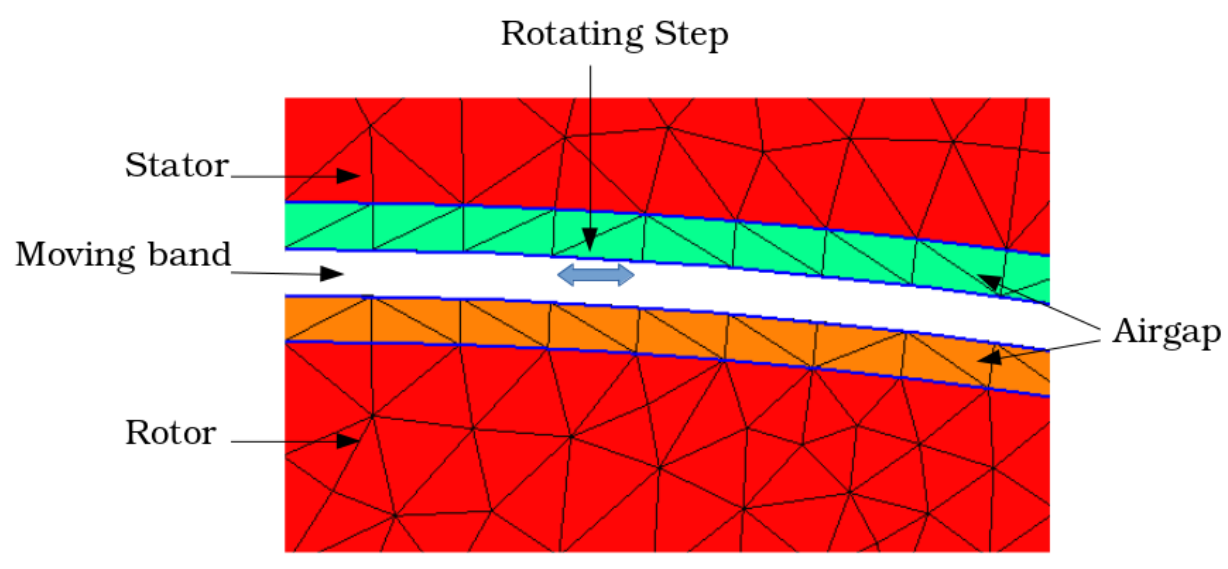

Figure 1: Application of meshing rules on 2D FEM example.

\subsection{Axial claw pole motor}

Unfortunately, axial flux machines induce an additional difficulty compared to radial flux machines. In the case of the ACPM, the meshing rules have to be respected on each radius from the internal to external radius as seen in Figure 2. The rotating step can be equal to the meshing step at each radius on stator and rotor only if the geometric lines are through radial axis. For the synchronous axial motor represented in Figure 2 with claw pole inductor and straight slots armature, this rules can not be applied.

Calculations are made with a periodic model meshed with really fine element (Figure 3). The magnetization curve $\mathrm{b}(\mathrm{h})$ used in the model is from a standard steel material as shown in Figure 4. The electric conductivity of copper is equal to $59.610^{6}(\mathrm{~S} / \mathrm{m})$. The armature is supplied with three-phase sinusoidal current. The boudary conditions are shown in Figure 5. The double airgap motor has an axial symetry and so the condition $\mathbf{b} \times \mathbf{n}$ is used on an area in the middle of the stator yoke. The torque can be computed by applying the Maxwell stress tensor $\left(\bar{T}_{m}\right)$ on a circular area in the airgap between the stator and the rotor. To reduce numerical noise the torque is calculated using an average of this surface integral on a thickness $e$ along the air gap $\left(\Omega_{e}\right)$ as presented in a study by (Fontchastagner et al. 2015). Calculation are made on two slot pitches for 32 positions. Instability on results from vector potential formulation is observed with an ordinary tetrahedral mesh in the air gap as seen in Figure 6. This kind of mesh does not allow to estimate high-order harmonics torque:

$$
\text { Torque }=\frac{1}{e} \int_{\Omega_{e}}\left(\mathbf{r} \times\left(\overline{\bar{T}}_{m} \cdot \mathbf{e}_{\mathbf{z}}\right) d \Omega\right) \cdot \mathbf{e}_{\mathbf{z}}
$$



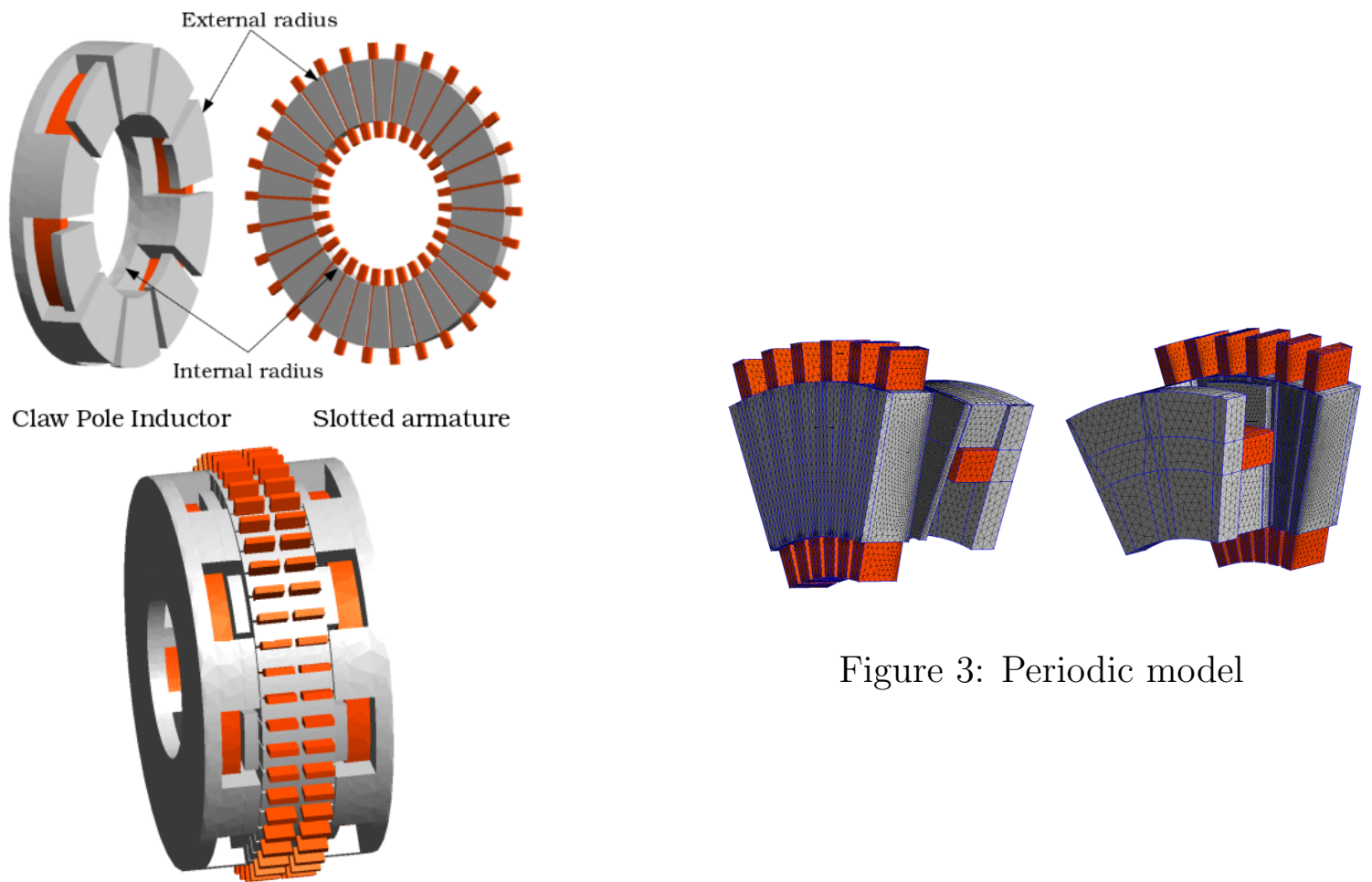

Figure 3: Periodic model

Figure 2: Synchronous axial claw pole motor

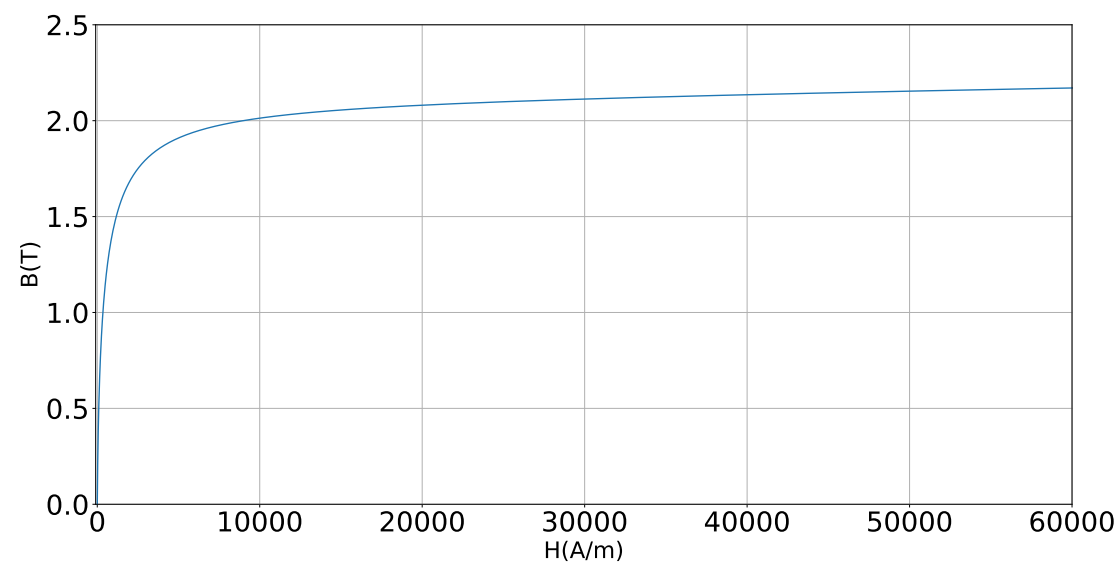

Figure 4: B-H curve of steel 


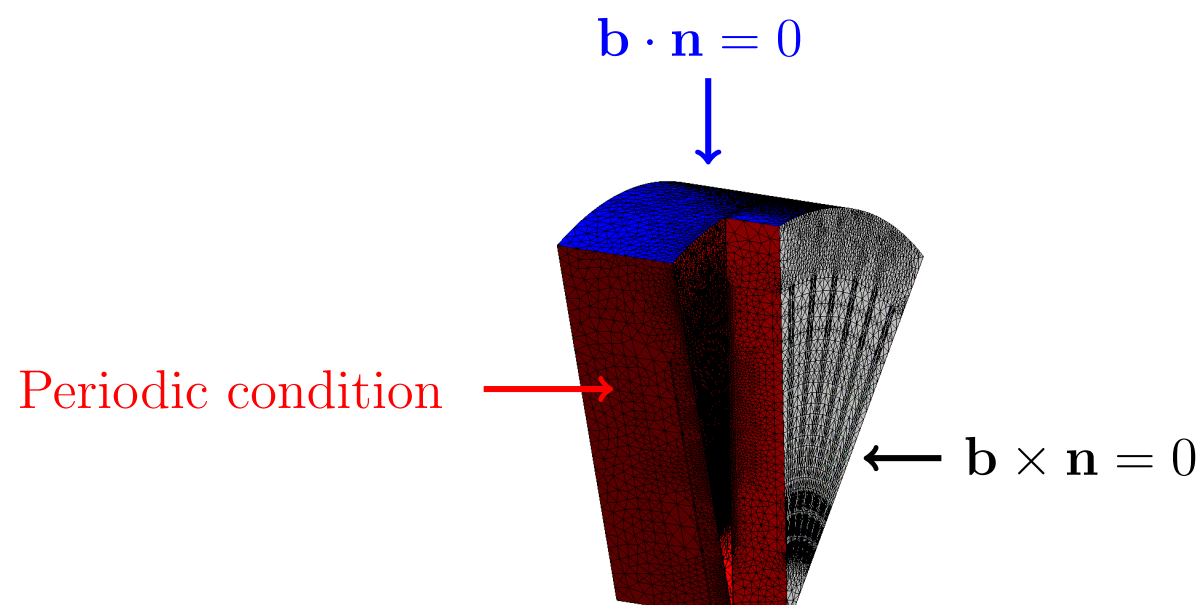

Figure 5: Boundary conditions 
To analyse the confidence about simulation results both formulations will be used. Using both formulations is essential in this study because only one magnetic continuity condition is imposed strongly using FEM(Bossavit 1998), which can leads to unaccuracies (Tarnhuvud \& Reichert 1988). In fact, the continuity of the normal component of the magnetic flux density $\mathbf{b}_{\mathbf{n}}$ is strongly imposed using the vector potential weak formulation and tangential component of the magnetic field strength $\mathbf{h}_{\mathbf{t}}$ is strongly imposed using the scalar potential weak formulation. This issue is not solved and is still a current research topic (Martinez et al. 2008)(Lefevre et al. 2018).

To strongly improve the mesh quality, we propose to split the airgap into four parts (see Figure 7). This method replaces a classical moving band. The torque is then calculated with equation(1) in the two central parts in which the meshing step of the structured mesh is equals to the rotating step as seen in Figure 8. The two other parts are used to connect the structured mesh on the central parts to the mesh on rotor and stator interface. Even if the problem is meshed for each position, the meshes will be similar in the central air gap for any configuration. With this mesh, torques from both the formulations are well calculated as seen in Figure 9. The differences between the results are mainly because of the weak formulations and much less because of the air-gap meshing problems as shown in Figure 6. However, scalar and vector potential formulations give different results. Facing these difficulties, the authors decided to investigate in the present work the creation of a procedure to evaluate the information contained in output data and to estimate the precision of the results for different meshes. 


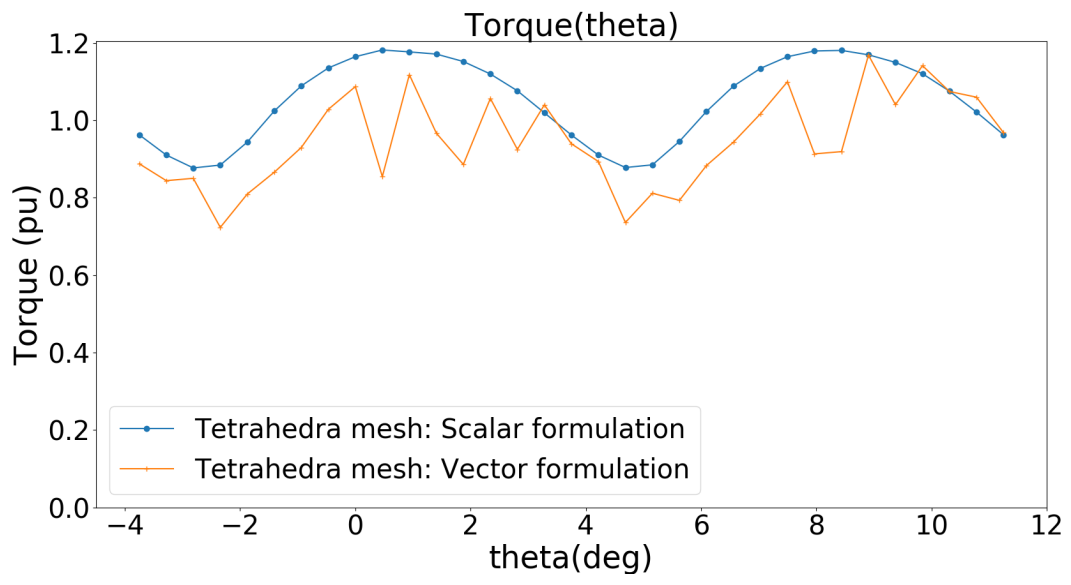

Figure 6: Torque with tetrahedra mesh

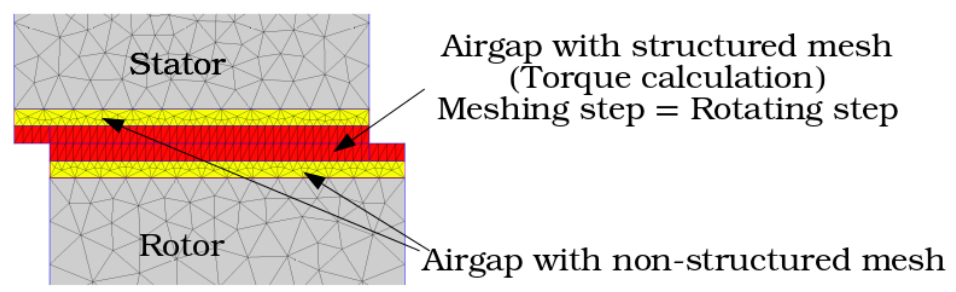

Figure 7: Airgap split into four parts

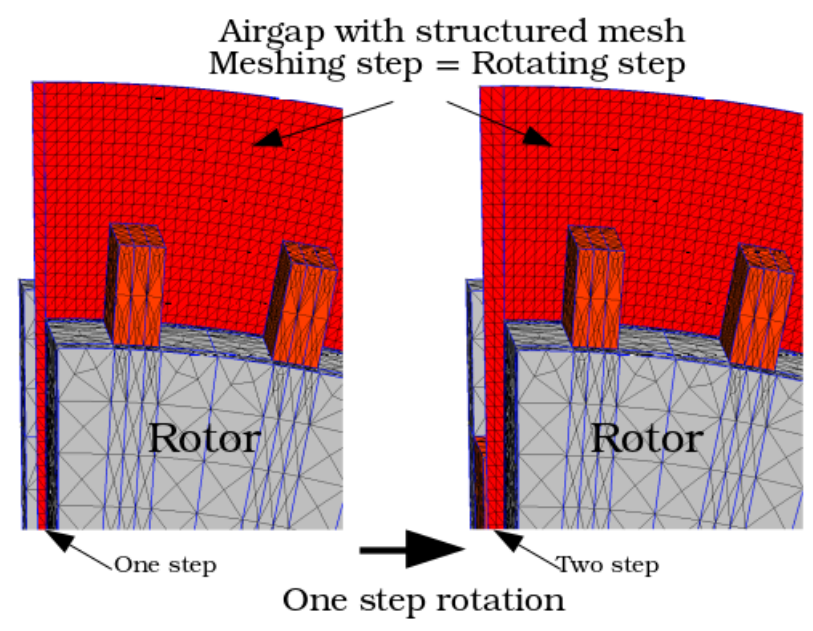

Figure 8: Structured mesh in airgap 


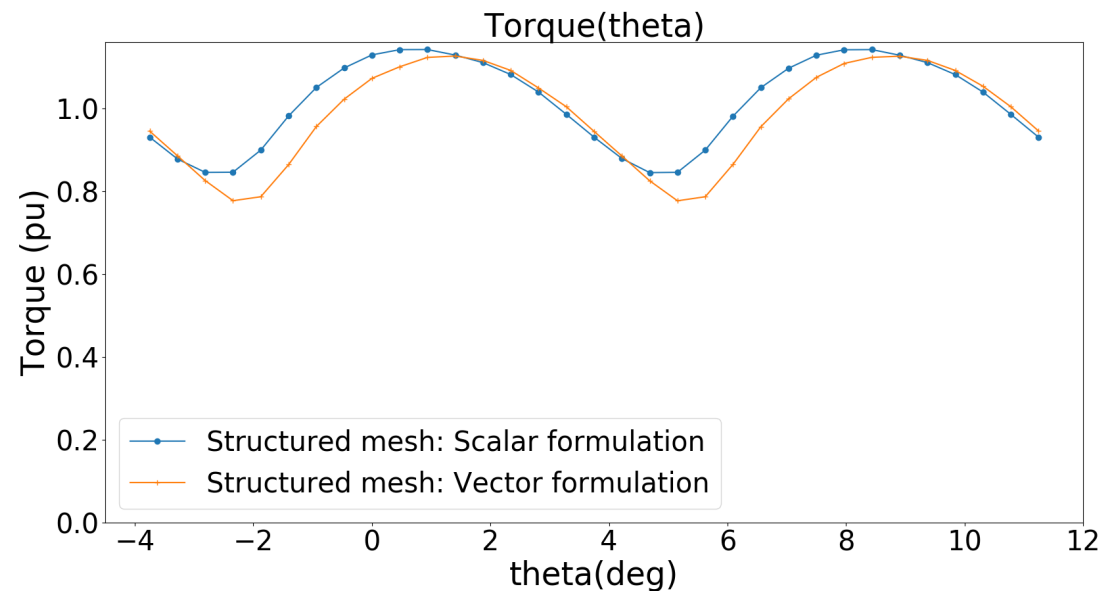

Figure 9: Torque with structured mesh

\section{Proposed approach}

The proposed method lies in a comparison between scalar and vector potential formulations. Such comparison between both formulations has already been used in several works (Dular, Geuzaine \& Legros 1999)(Dular, Henrotte \& Legros 1999). The aim is to evaluate the confidence level of high-order harmonics torque.

\subsection{Weak formulations}

A finite element magnetostatic problem can be describe with both scalar and vector potential formulations.

\section{- Scalar potential formulation:}

To use the magnetic scalar potential $\varphi$ in the weak formulation, a dummy magnetic field $\mathbf{h}_{\mathbf{s}}$ is calculated to replace the electric current density $\mathbf{j}$ in the sources domain $\Omega_{s}$ as:

$$
\begin{gathered}
\mathbf{j}=\boldsymbol{\nabla} \times \mathbf{h}_{\mathbf{s}} \\
\nabla \times\left(\mathbf{h}-\mathbf{h}_{\mathbf{s}}\right)=0 \\
\left(\mathbf{h}-\mathbf{h}_{\mathbf{s}}\right)=-\nabla \varphi
\end{gathered}
$$

Gauss's law for magnetism gives:

$$
\int_{\Omega} \boldsymbol{\nabla} \cdot \boldsymbol{b} d \Omega=\int_{\Omega} \boldsymbol{\nabla} \cdot\left(\mu\left(\boldsymbol{h}_{\boldsymbol{s}}-\boldsymbol{\nabla} \varphi\right)\right) d \Omega=0
$$

The weak form is:

$$
\int_{\Omega_{s}} \mu \mathbf{h}_{\mathbf{s}} \cdot \nabla \varphi^{\prime} d \Omega_{s}-\int_{\Omega} \mu \nabla \varphi \cdot \nabla \varphi^{\prime} d \Omega=0
$$




\section{- Vector potential formulation:}

As the magnetic flux density is divergence-free (Gauss's law for magnetism: $\boldsymbol{\nabla} \cdot \mathbf{b}=0$ ), a vector magnetic potential $\mathbf{a}$ always exists as $\mathbf{b}=\boldsymbol{\nabla} \times \mathbf{a}$. The Ampere- Maxwell law with $\mathbf{j}$ the electric current in the sources domain $\Omega_{s}$ gives:

$$
\iiint_{\Omega}\left(\boldsymbol{\nabla} \times\left(\frac{1}{\mu} \boldsymbol{\nabla} \times \mathbf{a}\right)\right) d \Omega-\iiint_{\Omega_{s}} \mathbf{j} d \Omega_{s}=0
$$

The weak formulation is:

$$
\int_{\Omega}\left(\frac{1}{\mu} \boldsymbol{\nabla} \times \mathbf{a}\right) \cdot\left(\boldsymbol{\nabla} \times \mathbf{a}^{\prime}\right) d \Omega-\int_{\Omega_{s}} \mathbf{j} \cdot \mathbf{a}^{\prime} d \Omega_{s}-\int_{d \Omega}\left(\left(\frac{1}{\mu} \boldsymbol{\nabla} \times \mathbf{a}\right) \wedge \mathbf{n}\right) \cdot \mathbf{a}^{\prime} d S=0
$$

\subsection{Proposed approach}

The aim is to study results consistency versus degrees of freedom (Dofs) number or mesh density. To make a fair comparison, the two calculations use the same mesh. The meshing step in the central air gap exactly equals the rotating step. However, in the motor, the mesh size depends on a reference length $l_{\text {ref }}$. Figure 10 and Figure 11 show, respectively, example with a small and a large $l_{\text {ref }}$.

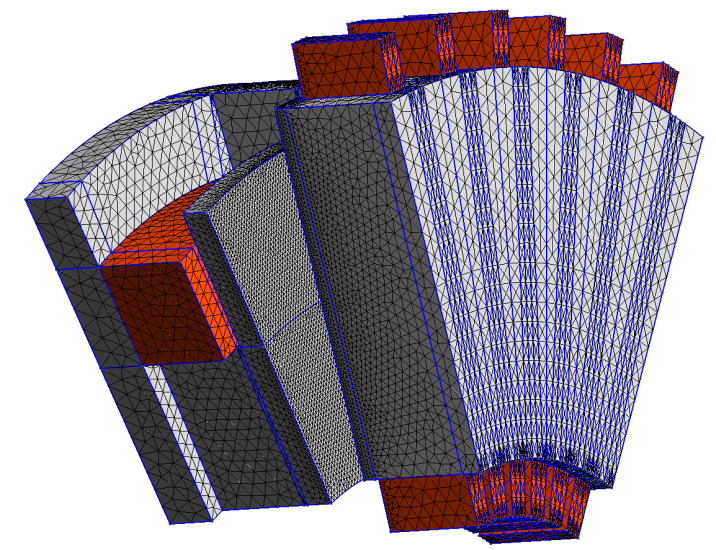

Figure 10: Small lref

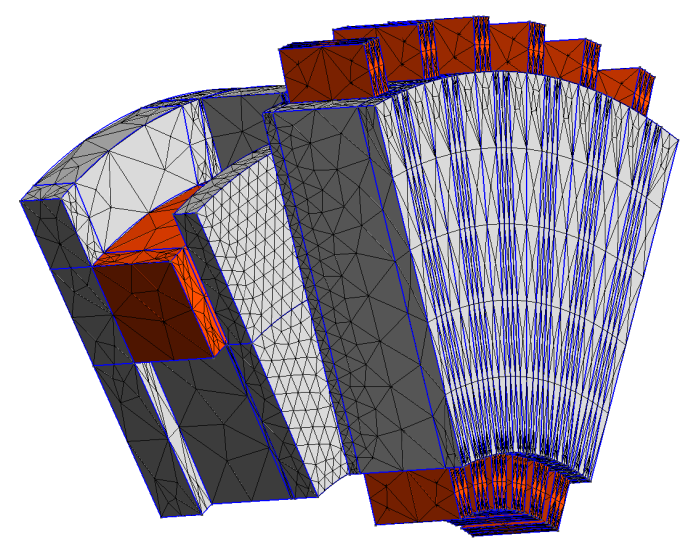

Figure 11: Large lref

The 15 different meshes, with 15 different $l_{\text {ref }}$, are used on the periodic model. The meshes range from very fine mesh (1390e3 Dofs for vector potential, 232e3 Dofs for scalar potential) to large mesh (185e3 Dofs for vector potential, $32 \mathrm{e} 3$ Dofs for scalar potential) as seen in Figure 12. Dofs number of vector potential formulation is 6 time higher than scalar potential in this model. This explains that the CPU time is lower with scalar formulation than with vector formulation as shown in the ratio $\frac{\text { CpuTimevector }}{\text { CpuTimescalar }}$ plot in red in Figure 12. For each mesh size, the torque is calculated on two slot pitches for 32 positions. 


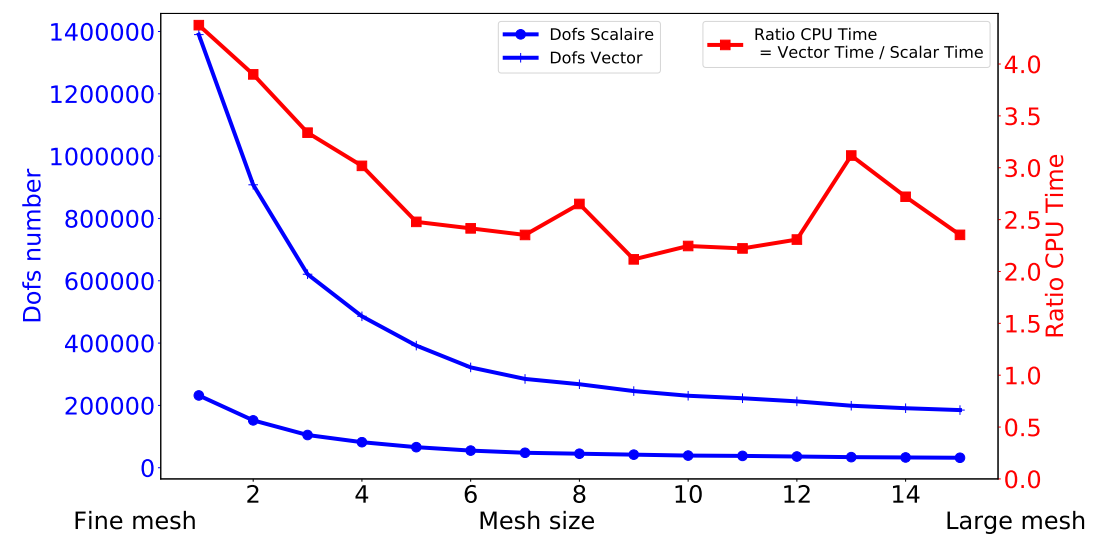

Figure 12: Dofs number and CPU time

\section{Results}

A spectral analysis on time-dependent torque is made using fast fourier transform (FFT). The study focusses on the mean value and the first four harmonics of torque. Differences between the two formulations and the evolutions of these quantities depending on the mesh size are investigated. To compare the two results, deviation and mean on the modulus coefficient of FFT, Co, for each harmonics and for each mesh are calculated with:

$$
\operatorname{Dev}(k)=\frac{C_{o_{\text {Scalar }}}(k)-C_{\text {Vector }}(k)}{\frac{C_{\text {Scalar }}(k)+\text { Co }_{\text {Vector }}(k)}{2}}
$$

and

$$
\operatorname{Mean}(k)=\frac{\operatorname{Co}_{\text {Scalar }}(k)+C_{\text {Vector }}(k)}{2}
$$

$\mathrm{k}$ being the harmonic rank.

All curves are plot with torque in per unit as:

$$
\text { Torque }_{(p u)}=\frac{\text { Torque }_{\text {actual }}}{\text { Torque }_{\text {Base }}}
$$

with

$$
\text { Torque }_{\text {Base }}=\frac{T_{\text {Scalar }}+T_{\text {Vector }}}{2}
$$

$T_{\text {Scalar }}$ and $T_{V e c t o r}$ being the mean value of torque from scalar and vector formulations for the finest mesh. Torques calculated with the finest and the lagest mesh are plot in Figure 13. There are differences between the two formulations which decrease with finer meshes. 


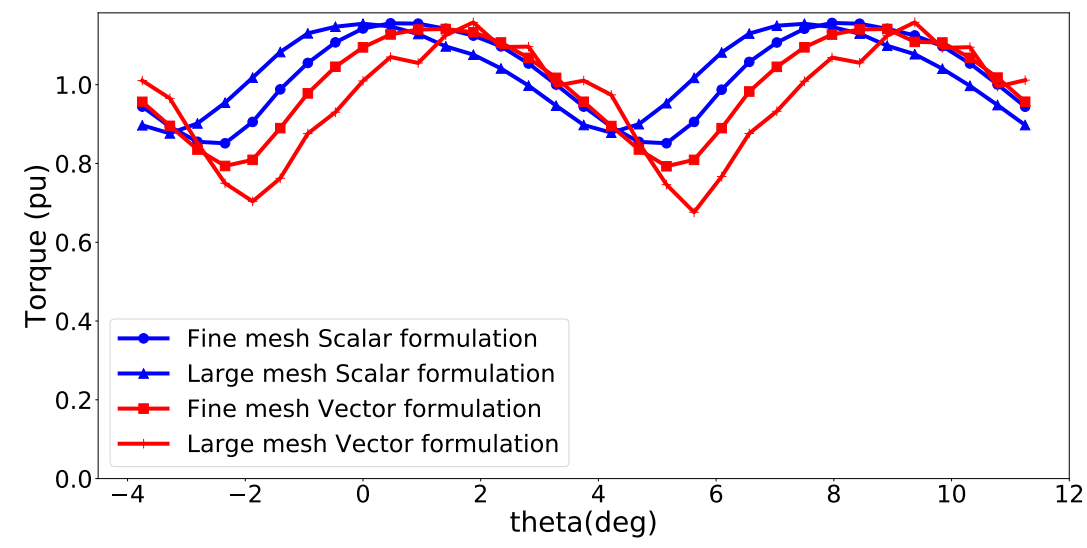

Figure 13: Torque

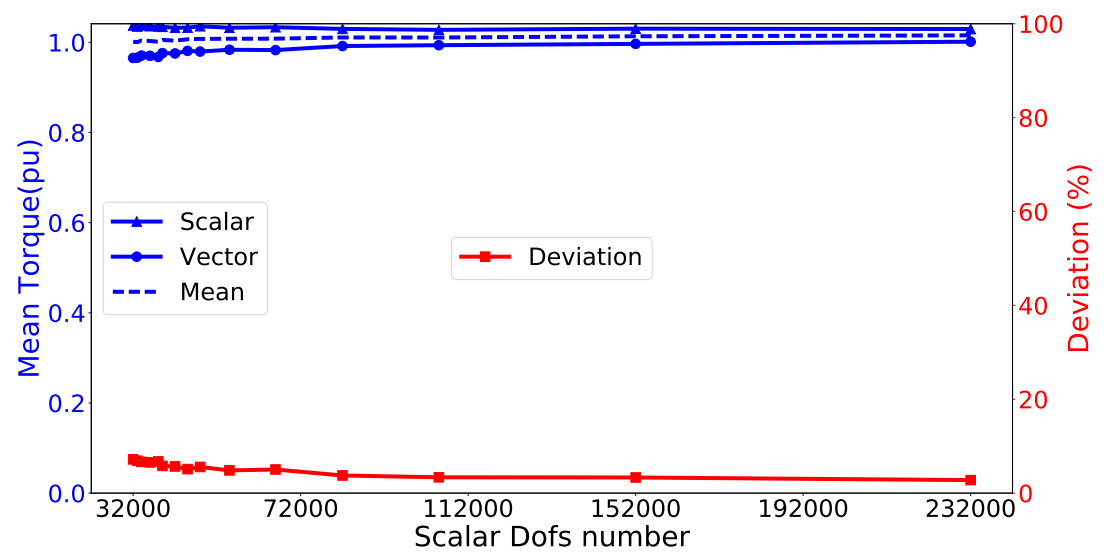

Figure 14: Mean torque

\section{- Torque mean value:}

The mean value and the deviation of torque versus the Dofs number are shown in Figure 14. With finer mesh, the deviation decrease. The torque mean value is calculated with a good accuracy even with large mesh size with $\operatorname{Dev}(k=0) \leq 7 \%$.

\section{- Torque harmonics:}

the deviation of the first and third harmonics decreases as Dofs number increases and the mean values of $C o$ between scalar and vector formulations are constant. It can be concluded that the first harmonic is calculated with a $\pm 10 \%$ accuracy, with scalar Dofs number $=232000$, up to $\pm 30 \%$ with scalar Dofs number $=50000$ (see Figure 15). A compromise has to be found between Dofs number (CPU time) and accuracy. The third harmonic can only be estimated with an accuracy from $\pm 45 \%$ with with scalar Dofs number $=232000$ up to $\pm 65 \%$ with scalar Dofs number $=70000$ (see Figure 16). 


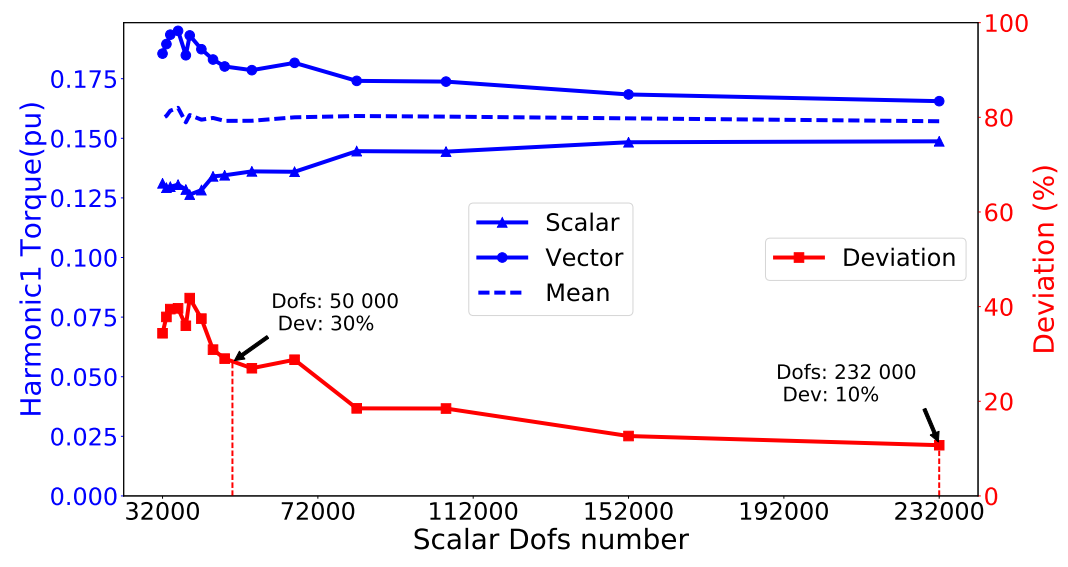

Figure 15: Torque: Harmonic 1

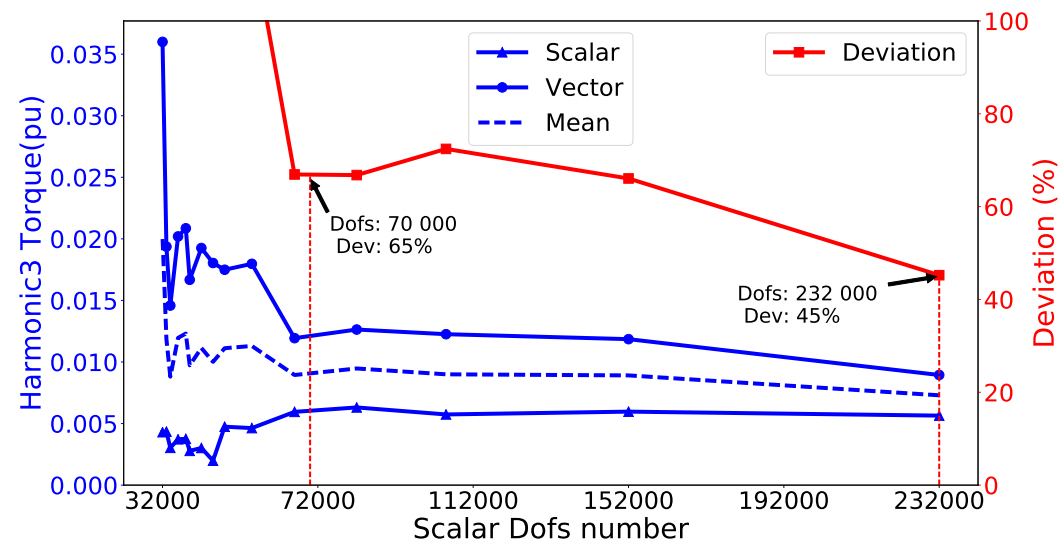

Figure 16: Torque: Harmonic 3

It is more difficult to conclude for Harmonics 2 and 4 (Figure 17, Figure 18). Unlike the previous point, the deviation for the second harmonic does not decrease with mesh size. Considering Figure 18, we found out the Harmonic 4 value (mean of scalar and vector formulations) continues to increase with Dofs number. As any steady state can be reached, we cannot choose a specific value. It is considered that there is no information on these harmonics with the considered mesh sizes. The Dofs number can not be more reduced because of time and CPU memory issues. 


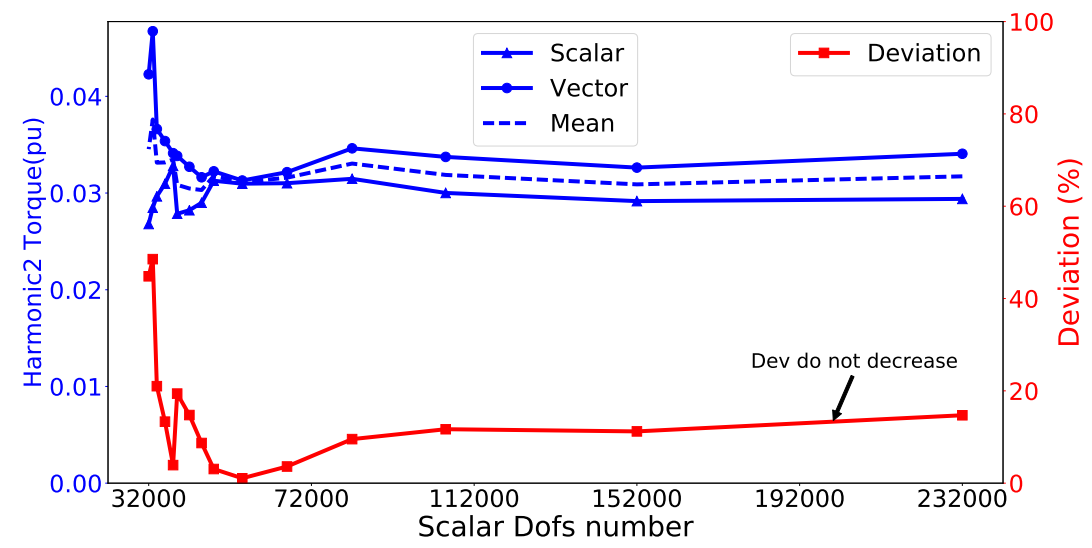

Figure 17: Torque: Harmonic 2

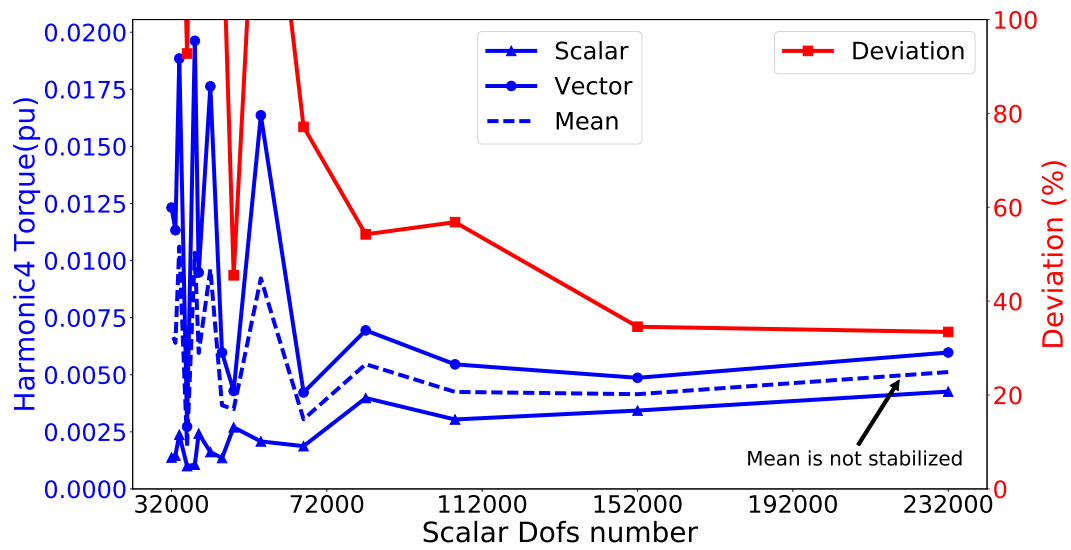

Figure 18: Torque: Harmonic 4 


\section{Conclusion}

An ACPM is a complex topology to study and leads to complications for FEM simulation. The results on this motor prove the need and the relevance of the method despite the fact that it is time-consuming. In fact, for the proposed motor and mesh, only the mean value (even with large mesh) and the first harmonic (with fine mesh) are calculated with a good accuracy. The non-respect of the meshing rules has a strong impact on the results, which has to be analyzed. Moreover, scalar and vector formulations do not give exactly the same results and a finite elements model has to be validated by using both formulations. An analysis of the results obtained using finite element method is essential before any vibration calculation based on torque harmonics values. The method presented in this paper can be used to better identify harmonics accurately calculated for any kind of topology.

\section{References}

Beccue, P., Neely, J., Pekarek, S. \& Stutts, D. (2005), 'Measurement and control of torque ripple-induced frame torsional vibration in a surface mount permanent magnet machine', IEEE Transactions on Power Electronics 20(1), 182-191.

Bossavit, A. (1998), 'How weak is the weak solution in finite elements methods?', Magnetics, IEEE Transactions on MAG-34, 2429 - 2432.

Chaieb, M., Tounsi, S., Neji, R. \& Sellami, F. (2008), Optimum geometry for torque ripple minimization of permanent magnet motor by the finite element method, in 'MELECON 2008 - The 14th IEEE Mediterranean Electrotechnical Conference', pp. 459-464.

Davat, B., Ren, Z. \& Lajoie-Mazenc, M. (1985), 'The movement in field modeling', IEEE Transactions on Magnetics 21(6), 2296-2298.

Dular, P. \& Geuzaine, C. (2019), 'GetDP reference manual: the documentation for GetDP, a general environment for the treatment of discrete problems'. http://getdp. info.

Dular, P., Geuzaine, C. \& Legros, W. (1999), 'A natural method for coupling magnetodynamic h-formulations and circuit equations', IEEE Transactions on Magnetics 35(3), 1626-1629.

Dular, P., Henrotte, F. \& Legros, W. (1999), 'A general and natural method to define circuit relations associated with magnetic vector potential formulations', IEEE Transactions on Magnetics 35(3), 1630-1633. 
Fontchastagner, J., Lubin, T., Messine, F. \& Mezani, S. (2015), 'Efficient design using successive analytical subproblems method: Application to axial magnetic couplings', IEEE Transactions on Magnetics 51(3), 1-4.

Geuzaine, C. \& Remacle, J.-F. (2009), 'Gmsh: A three-dimensional finite element mesh generator with built-in pre-and post-processing facilities', International Journal for Numerical Methods in Engineering 79, 1309-1331.

Labbe, N. \& Savinois, O. (2017), 'Flux switching rotating electrical machine for traction for a motor vehicle'.

Lee, J. \& Ha, J. (2018), Harmonic torque reduction using adaptive sector-based torque feedforward method for pmsm, in '2018 IEEE Energy Conversion Congress and Exposition (ECCE)', pp. 5473-5478.

Lefevre, Y., Henaux, C. \& Llibre, J. F. (2018), 'Magnetic field continuity conditions in finite-element analysis', IEEE Transactions on Magnetics 54(3), 1-4.

Martinez, N., Lefevre, Y. \& Nogarede, B. (2008), 'Strong formulation using fds, weak formulation using fem and experimental data'.

Nam, M. J., hyun Kim, J., Cho, K.-Y., Kim, H.-W. \& Cho, Y. (2017), Torque ripple reduction of an interior pm synchronous motor by compensating harmonic currents based on flux linkage harmonics.

Tarnhuvud, T. \& Reichert, K. (1988), 'Accuracy problems of force and torque calculation in fe-systems', IEEE Transactions on Magnetics 24(1), 443-446.

Wu, H., Depernet, D. \& Lanfranchi, V. (2019), 'Analysis of torque ripple reduction in a segmented-rotor synchronous reluctance machine by optimal currents', Mathematics and Computers in Simulation 158, 130 - 147.

Zhao, W., Lipo, T. A. \& Kwon, B. (2015), 'Torque pulsation minimization in spoketype interior permanent magnet motors with skewing and sinusoidal permanent magnet configurations', IEEE Transactions on Magnetics 51(11), 1-4.

Zhu, Z. Q. \& Leong, J. H. (2012), 'Analysis and mitigation of torsional vibration of pm brushless ac/dc drives with direct torque controller', IEEE Transactions on Industry Applications 48(4), 1296-1306. 